\title{
Active Power Dispatch Plan among Units in DFIG Based Wind Farm
}

\author{
Lefeng Zhang \\ School of Electrical \& Electronic Engineering, North China Electric Power University, Beijing, 102206, China \\ E-mail:443692711@qq.com \\ Zengping Wang \\ School of Electrical \& Electronic Engineering, North China Electric Power University, Beijing, 102206, China \\ E-mail:wangzp1103@sina.com
}

Received 23 February 2014

Accepted 2 April 2014

\begin{abstract}
During normal operation, doubly-fed induction generator (DFIG) can generate certain range of reactive power according to the requirements of the power grid. According to the active power order from power dispatching center, a kind of wind turbines scheduling solution which also suits the actual operation situation of "three-north" area wind farms in China is proposed. This solution makes it possible for the wind farm to generate the maximum reactive power or the certain reactive power below the maximum reactive power which will meet the needs of the power grid by adjusting output active power and reactive power of each DFIG. Based on the DFIG reactive power limit, this paper proposes two theorems and an allocation algorithm to find out the active power dispatch plan. This plan avoids the grid side converter switch devices frequently action. The active power and reactive power generated by the wind farm can both satisfy the power grid's needs and provide a reference for the capacity of additional reactive power compensation device. The effectiveness of the active power and reactive power dispatch plan is verified in case study.
\end{abstract}

Keywords: Wind power curtailment; DFIG; reactive power limit; active power allocation

\section{Introduction}

China wind power industry has developed rapidly in recent years. Now wind power installation capacity of China is greater than that of the United States and has become the top of the world. Any sort of emergence of wind farms of large capacity inevitably affects the safe and stable operation of the power grid, especially the voltage stability. At present wind farms are required to have the ability of Low Voltage Ride Through ${ }^{1-2}$ (LVRT). If there is a short-circuit fault in grid power, wind farm must provide adequate reactive power to restore the grid voltage. Thus, the reactive power generated by the wind farm is directly related to the stability of power grid voltage, and reactive power compensation problem has become a study hotspot.

This paper was supported by the Fundamental Research Funds for the Central Universities of China.
Wind power curtailment caused by all kinds of factors $^{3}$ has become a big challenge to global wind power development, especially in China. The capacity of wind power curtailment, only in 2011 , is up to 12.3 billion $\mathrm{KWH}$, wind power curtailment rate is about 16 percent. The data from Chinese Wind Energy Association show that in 2012 the capacity of wind power curtailment in China is almost 20 billion KWH which causes economic losses more than 10 billion RMB. Therefore, wind power curtailment has become a common phenomenon. When it comes to the wind power, we must consider the wind power curtailment.

The wind power curtailment refers to the fact that the active power generated by the wind farm is lower than the maximum output ability of the wind farm. The wind power curtailment capacity does not include the power misses caused by equipment failure. Usually the power 
dispatching center gives an active power order to wind farm, according to current wind speed. When the active power generated by wind farm is over the active power order value, the wind power curtailment happens, then wind farm must reduce its output power. How to adjust active power generated by every wind turbine to make the wind farm send optimal reactive power is the main problem in this paper.

Many scholars have studied on reactive power compensation about wind farm. Refs. 4-7 study the advantage of Static Var Compensator (SVC) on reactive power compensation. Refs. 8-13 study the function of Static Synchronous Compensator (STATCOM). Ref. 14 improves traditional DVR device, greatly enhance the LVRT ability of wind turbine. Based on the stator side and grid side reactive power limit, different reactive power control strategies are proposed in Refs. 15-17.

Most scholars have focused on the additional reactive power compensation device, such as its capacity ${ }^{18}$ or control strategy based on some objective functions ${ }^{19-22}$. They usually do not take the wind power curtailment into account. This paper studies the ability of the DFIG based wind farm inherent reactive power compensation. The reactive power generated by different active power dispatch plans differs and it is directly related to the safe and stable operation of power gird. So, it is important to find out the reactive power limit of wind farm in certain condition. This paper analyses the reactive power upper limit and lower limit of wind farm. According to the active power order from power dispatching center, a scheduling scheme about how to distribute active power and reactive power among all wind turbines with double fed induction generators is proposed. This scheme in accord with actual operation situation in "three-north" area wind farms in China and the reactive power generated by wind farm can be controlled. If the reactive power generated by wind farm can meet the power grid's demand, the additional reactive power compensation device does not need to work, so this scheme reduces the operation cost and the switching on/off times of additional reactive power compensation device.

\section{The Basic Strategy of Reactive Power Control}

Wind farm reactive power control strategy is generally divided into the following two levels. ${ }^{23}$

- The reactive power cooperation between the wind farm and the power grid, including the reactive power generated by additional reactive power compensation device.
- How to distribute this demand value among all the units when the wind farm gets a reactive power demand of power grid.

This paper mainly finds out the reactive power limit of wind farm by adjusting active power generated by every DFIG.

DFIG rotor connects power grid by a converter which can generate certain range of adjustable reactive power for power grid. The paper considers inductive reactive power positive. When power dispatching center gives an active power order to wind farm, at the same time, the wind farm control center need obey the order and select each wind turbine to generate certain active power and reactive power. The structure chart of the wind farm control process is shown in figure 1.

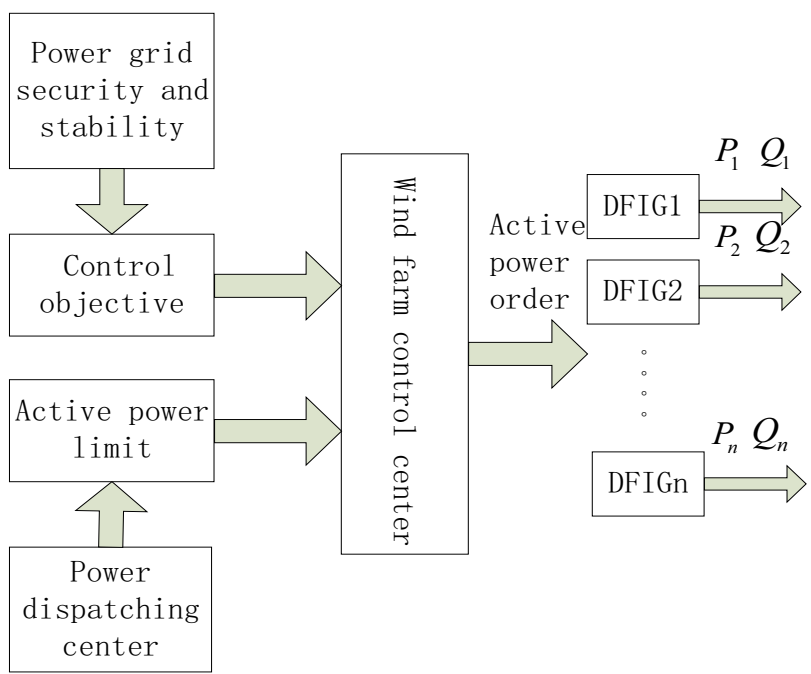

Fig.1. Wind farm control structure chart

\section{Reactive Power Limit of DFIG Considering Wind Power Curtailment}

Voltage Oriented Control (VOC) system for DFIG is adopted in this paper, the stator reactive power limit of $\operatorname{DFIG}\left(Q_{s \min }\right.$ and $\left.Q_{s \max }\right)$ is as follows ${ }^{15}$ :

$Q_{s \min }=-\frac{3 U_{s}^{2}}{2 X_{s}}-\sqrt{\left(\frac{3}{2} \frac{X_{m}}{X_{s}} U_{s} I_{r \max }\right)^{2}-P_{s}^{2}}$

$Q_{s \max }=-\frac{3 U_{s}^{2}}{2 X_{s}}+\sqrt{\left(\frac{3}{2} \frac{X_{m}}{X_{s}} U_{s} I_{r \max }\right)^{2}-P_{s}^{2}}$

Where $U_{s}$ is power grid voltage, $X_{s}$ is stator resistance, $X_{m}$ is magnetizing resistance, $I_{r \max }$ is the maximum current passing through rotor converter, and 
$P_{s}$ is stator active power. From equation (1)-(2) we can see that for a given DFIG, $U_{s} 、 X_{s} 、 X_{m} 、 I_{r \max }$ are all constants, $Q_{s \min }$ and $Q_{s \max }$ are determined by $P_{s}$, $P_{s}$ is determined by not only wind speed but also wind power curtailment. That is to say, when wind power curtailment happens, some units need to reduce their output power, $P_{s}$ changes and then $Q_{s \min } 、 Q_{s \max }$ change too. For a given wind speed, if wind power curtailment happens, the stator reactive power limit of $\operatorname{DFIG}\left(Q_{s \min }\right.$ ' and $\left.Q_{s \max }{ }^{\prime}\right)$ is changed to

$$
\begin{aligned}
& Q_{s \min }{ }^{\prime}=A-\sqrt{B-P_{s}^{\prime 2}} \\
& Q_{s \max }{ }^{\prime}=A+\sqrt{B-P_{s}^{\prime 2}}
\end{aligned}
$$

Where $A=-\frac{3 U_{s}^{2}}{2 X_{s}}, B=\left(\frac{3}{2} \frac{X_{m}}{X_{s}} U_{s} I_{r \max }\right)^{2}, A$ and $B$ are all constants, $P_{s}^{\prime}$ is changing stator active power, $P_{s}^{\prime}<P_{s}$.

Grid-side converter (GSC) usually works in the unit power factor mode, namely $Q_{c}=0$. In this mode, gridside converter does not take part in reactive power regulation. If GSC works in the other power factors, reactive power limit of GSC $\left(Q_{c \min }\right.$ and $\left.Q_{c \max }\right)$ is:

$$
\begin{aligned}
& Q_{c \text { min }}=-\sqrt{S_{c}^{2}-[s /(1-s)]^{2} P_{s}^{2}} \\
& Q_{c \text { max }}=\sqrt{S_{c}^{2}-[s /(1-s)]^{2} P_{s}^{2}}
\end{aligned}
$$

Where $S_{c}$ is GSC capacity, $s$ is slip. Unlike the stator reactive power limit, reactive power limit of GSC is determined by both $s$ and $P_{s}$.

The reactive power limit of DFIG $\left(Q_{g \text { max }}\right.$ and $Q_{g \text { min }}$ ) is the sum of stator reactive power limit and GSC reactive power limit:

$$
\begin{aligned}
& Q_{g \text { max }}=Q_{s \text { max }}+Q_{c \text { max }} \\
& Q_{g \text { min }}=Q_{s \text { min }}+Q_{c \text { min }}
\end{aligned}
$$

GSC capacity is small, so its reactive power regulation ability is very limited and in order to reduce the losses of converter switch device, DFIG should make the stator participate in reactive power regulation first. Accordingly, this paper does not consider the GSC reactive power regulation, namely:

$$
\begin{aligned}
& Q_{g \max } \approx Q_{s \max } \\
& Q_{g \text { min }} \approx Q_{s \min }
\end{aligned}
$$

According to formula (9) and (10), reactive power limit of DFIG is relatively conservative. It gives every DFIG more reactive power margin and it is good to safe and stable operation of power gird.

\section{Reactive Power Limit of DFIG Based Wind Farm}

\subsection{Principle of wind power curtailment}

For wind farms in the "three-north" area in china, the wind resource in winter is optimal. Since heat load is large, thermal power plant is first choice, and wind power curtailment is the most common phenomenon in winter. On the other hand, the temperature of "three-north" area is rather low in winter. If the wind turbine is shut down, the machine components may be damaged by low temperature. To protect the wind turbine, the wind turbine needs to keep working. To accelerate the response speed, the wind turbine needs to keep working, too.

When wind power curtailment happens, in order to make every DFIG keep a certain reactive power margin, we hope that the one with greater reactive power limit undertakes more reactive power task.

\subsection{Reactive power limit of DFIG wind farm considering wind power curtailment}

Assuming there are $N$ wind turbines with double fed induction generators in wind farm, DFIG $i$ generates active power $p_{i}$ (the active power generated by DFIG replaces the stator active power), and then the reactive power limit of the whole wind farm is as follows:

$$
\begin{aligned}
Q_{P_{i} \max } & =\sum_{i=1}^{N} Q_{i \max }=\sum_{i=1}^{N} f_{1}\left(p_{i}\right) \\
& =\sum_{i=1}^{N}\left(A+\sqrt{B-P_{i}^{2}}\right) \\
Q_{P_{i} \min } & =\sum_{i=1}^{N} Q_{i \min }=\sum_{i=1}^{N} f_{2}\left(p_{i}\right) \\
& =\sum_{i=1}^{N}\left(A-\sqrt{B-P_{i}^{2}}\right)
\end{aligned}
$$


Where $Q_{i \max }$ and $Q_{i \min }$ are reactive power limit of DFIG $i, Q_{P_{i} \max }$ and $Q_{P_{i} \text { min }}$ are the reactive power limit of the whole wind farm respectively.

When power dispatching center gives an active power order to the wind farm, the wind farm control center adopts different scheduling schemes, which change $p_{i}$, $Q_{P_{i} \max }$ and $Q_{P_{i} \text { min }}$ will change, too. In order to give full play to the reactive power ability of the wind farm, we need determine the maximum reactive power limit of the whole wind farm $\left(Q_{\mathrm{Fmax}}\right.$ and $\left.Q_{\mathrm{Fmin}}\right)$ when the wind farm generates active power value which is $P_{T}$. Compared with thermal power plant, wind farm has a low cost and produces nearly no pollution. Therefore, we want to find a plan which meets both needs of reactive power and active power of power grid, then the additional reactive power compensation does not need to start, thus reduces equipment on/off times and operation cost of the external reactive power.

When wind farm output active power value $P_{T}$ is given, to determine the maximum reactive power limit of the whole wind farm ( $Q_{\text {Fmax }}$ and $\left.Q_{\text {Fmin }}\right)$, we can establish the following optimization problems (M1) and (M2).

$$
\begin{aligned}
& \left\{\begin{array}{l}
\max \left(\sum_{i=1}^{N} Q_{i \max }\right)=\sum_{i=1}^{N} f_{1}\left(p_{i}\right)=\sum_{i=1}^{N}\left(A+\sqrt{B-P_{i}^{2}}\right) \\
\sum_{i=1}^{n} P_{i}=P_{T} \\
P_{i \min } \leq P_{i} \leq P_{i \max }
\end{array}\right. \\
& \left\{\begin{array}{l}
\min \left(\sum_{i=1}^{N} Q_{i \min }\right)=\sum_{i=1}^{N} f_{2}\left(p_{i}\right)=\sum_{i=1}^{N}\left(A-\sqrt{B-P_{i}^{2}}\right) \\
\sum_{i=1}^{n} P_{i}=P_{T} \\
P_{i \min } \leq P_{i} \leq P_{i \max }
\end{array}\right.
\end{aligned}
$$

Where $P_{T}$ is a given active power value from power dispatching center, the optimal value of (M1) and (M2) are $Q_{\mathrm{Fmax}}$ and $Q_{\mathrm{Fmin}}, Q_{i}$ is reactive power generated by DFIG $i$. If $V_{i}$ is less than rated wind speed, $P_{i \max }=\frac{1}{2} \times \pi R^{2} \times \rho_{\text {ai } \mathrm{r}} \times C_{p \max } \times V_{i}^{3}, V_{i}$ is the input wind speed of DFIG $i, R$ is the blade radius, $\rho_{\text {ai } r}$ is the air density, $C_{p \max }$ is the maximum power coefficient, if $V_{i}$ is greater than or equal to rated wind speed, $P_{i \max }=P_{N}, P_{N}$ is rated power of DFIG.

\section{Method of Two Layers Power Allocation}

\subsection{Principle of Two Layers Power allocation}

The active power order from power dispatching center is $P_{T}$ and reactive power demand is $Q_{N}$. Since the inductive reactive power is related to voltage, we consider only reactive power upper limit. There are two cases:

- If $Q_{N} \notin\left[0, Q_{F \max }\right]$, we need to start the external reactive power compensation equipment, compensation capacity is $Q_{N}-Q_{F \max }$ or greater than $Q_{N}-Q_{F \max }$

- If $Q_{N} \in\left[0, Q_{F \max }\right]$, we can meet the requirement of reactive power demand $Q_{N}$ by distributing the reactive power among the wind turbines. On the basis of the active power order $P_{T}$, we assume wind farm reactive power is $Q_{T}$ :

$$
Q_{T}=\sum_{i=1}^{N} Q_{i}=Q_{N}
$$

Where $Q_{T}$ is reactive power generated by wind farm, $Q_{i}$ is reactive power generated by DFIG $i$.

In order to meet both requirements of active power and reactive power, we adopt a method of two layers power allocation. In the first layer, we distribute active power and verify whether $Q_{P_{i} \text { max }} \geq Q_{N}$ based on this active power allocation, if yes, the first layer allocation is effective, otherwise we need to find other active power allocation. In the second layer, we distribute reactive power. On the basis of the first layer active power allocation, the reactive power allocation principle is as follows ${ }^{15}$ :

$$
Q_{i}=\left(Q_{i \max } / Q_{P_{i} \max }\right) Q_{N}
$$

We can see that the first layer active power allocation is the key step of the method of two layers power allocation.

\subsection{Workable active power and reactive power allocation plan}

When wind power curtailment happens, units in the wind farm fail to operate with full load. In normal situation, the 
active power generated by wind farm is inevitably greater than $P_{T}$, that is $\sum_{i=1}^{N} P_{i \max }>P_{T}$. Therefore, there is definitely an effective active power allocation plan, and the key is to find the active power allocation plan which makes the reactive power generated by wind farm equal or greater than $Q_{\mathrm{N}}$. A workable active power allocation plan is as follows:

$$
P_{i}=\frac{P_{T}}{\sum_{i=1}^{N} P_{i \max }} P_{i \max }
$$

Where $P_{i}$ is the active power generated by unit $i$ and it is one of the effective active power plans. Assuming that a wind farm is composed of $N$ wind turbines with the same type of double fed induction generators, when all the $P_{i \max }$ is same, $P_{i}=\frac{1}{N} P_{T}$, that is to say, the distribution of active power among each units is average. This plan also accords with the operation principle of the wind turbines in "three-north" area proposed in this paper, keeping every unit working in the wind farm.

Now we will prove that the plan of average distribution of active power among each units can meet the requirement of reactive power, In other words, according to this plan, $Q_{P_{i} \max }$ is greater than $Q_{N}$.

Theorem 1. Assuming that a wind farm is composed of $N$ wind turbines with the same type of double fed induction generators, and power dispatching center sends active power order $P_{T}$, average distribution of active power among $N$ units will make the reactive power generated by the wind farm the very maximum reactive power limit of the whole wind farm $Q_{F \max }$.

Proof. $Q_{F \max }$ is the maximum value of (M1). In order to prove $P_{i}=\frac{1}{N} P_{T}$ is the extreme point of (M1), let's construct the Lagrange function as follows:

$$
\begin{gathered}
G\left(P_{i}, \lambda\right)=\sum_{i=1}^{N}\left(A+\sqrt{B-P_{i}^{2}}\right)+\lambda\left(\sum_{i=1}^{N} P_{i}-P_{T}\right) \\
\left\{\begin{array}{l}
\frac{\partial G}{\partial p_{i}}=\frac{-p_{i}}{\sqrt{B-P_{i}^{2}}}+\lambda=0, i=1,2, \cdots, N \\
\frac{\partial G}{\partial \lambda}=\sum_{i=1}^{N} P_{i}-P_{T}=0
\end{array}\right.
\end{gathered}
$$

Namely,

$$
\left\{\begin{array}{l}
-p_{i}+\lambda \sqrt{B-P_{i}^{2}}=0, i=1,2, \cdots, N \\
\sum_{i=1}^{N} P_{i}-P_{T}=0
\end{array}\right.
$$

Worked out,

$$
\begin{gathered}
P_{i}=\frac{1}{N} P_{T}, i=1,2, \cdots, N, \\
\lambda=\frac{P_{i}}{\sqrt{B-P_{i}^{2}}}=\frac{P_{T}}{\sqrt{N^{2} B-P_{T}^{2}}} .
\end{gathered}
$$

Because the objective function in (M1) has extreme value and possible extreme point is unique, $P_{i}=\frac{1}{N} P_{T}, i=1,2, \cdots, N$ is maximum point of (M1).

Therefore, average distribution of active power among $N$ units will make the reactive power generated by wind farm be $Q_{F \max }$ and this $Q_{F \max }$ is definitely greater than $Q_{N}$. As a result, average distribution of active power is effective, the second layer of reactive power allocation uses the method proposed in Ref. 15, because $Q_{i \max }$ are all the same, the second layer is average distribution of reactive power among $N$ units, that is to say reactive power generated by every DFIG is $Q_{i}=\frac{1}{N} Q_{N}$. For $Q_{N} \leq Q_{P_{i} \max }=Q_{F \max }$, all the $Q_{i}$ will not exceed reactive power upper limit.

\subsection{Workable active power allocation plan considering wake effect}

In the process of the actual operation, different wind turbines of the wind farm often get different input wind speed caused by factors such as wake effect and terrain, so the maximum output of every DFIG is not the same, some units can not generate the average active power $\frac{P_{T}}{N}$. In this situation, we need to find a new workable active power allocation plan.

Theorem 2. Assuming that wind farm is composed of $N$ wind turbines with the same type of double fed induction generator, $P_{i}, P_{i \max }$ are active power and the maximum active power generated by unit $i$ respectively, $i=1,2, \cdots, N, P_{1 \max } \leq P_{2 \max } \leq \cdots \leq P_{N \max }$, then there exists $k$ subject to 


$$
P_{i}=\left\{\begin{array}{l}
P_{i \max }, \quad i=1,2, \cdots, k \\
P_{i}=\frac{P_{T}-\sum_{i=1}^{k} P_{i \max }}{N-k}, i=k+1, k+2, \cdots, N
\end{array}\right.
$$

When this active power allocation plan is conducted, the reactive power limit of the whole wind farm is just $Q_{F \max }$.

Proof. From $f_{1}\left(P_{i}\right)=A+\sqrt{B-P_{i}^{2}}$ we can get $f_{1}^{\prime}\left(P_{i}\right)<0, f_{1}\left(P_{i}\right)$ is decreasing function, if $P_{i}^{\prime}<P_{i}^{\prime \prime}$, $\left|f_{1}^{\prime}\left(P_{i}^{\prime}\right)\right|<\left|f_{1}^{\prime}\left(P_{i}^{\prime \prime}\right)\right|, f_{1}\left(P_{i}\right)$ declines faster and faster as $P_{i}$ increases, hence, if $P_{i}$ is lower than $\frac{P_{T}}{N}$ by $\Delta P_{i}$, the other units need to increase by $\Delta P_{i}$, then $Q_{P_{i} \max }=\sum_{i=1}^{N} f_{1}\left(p_{i}\right) \quad$ is definitely declining. Consequently, the units which cannot output $\frac{P_{T}}{N}$ generate the maximum active power $P_{i \max }$, the rest of units averagely undertake the rest of active power, and the reactive power limit of the whole wind farm is just $Q_{F \max }$.

However, the rest of average active power is over $\frac{P_{T}}{N}$. Possibly some units cannot output the average new active power, so we give an allocation algorithm to solve this problem. In fact, the size of the $P_{1 \text { max }}, P_{2 \max }, \cdots, P_{N \text { max }}$ is in accordance with the size of wind speed, i.e. if $V_{1} \leq V_{2} \leq \cdots \leq V_{N}$, then $P_{1 \text { max }} \leq P_{2 \max } \leq \cdots \leq P_{N \text { max }}$.

The main steps of this algorithm are described as follows:

Step1 Input numbers of units $N$, wind speed $V_{i}(i=1,2, \cdots, N)$ according to $V_{1} \leq V_{2} \leq \cdots \leq V_{N}$, active power order $P_{T}$, and other parameters of every DFIG.

$$
\text { Step2 Let } S=\left\{P_{1}, P_{2}, \cdots, P_{N}\right\}=\{0,0, \cdots, 0\}
$$

Step3 If $P_{1 \max } \geq \frac{P_{T}}{N}$, let $P_{i}=\frac{P_{T}}{N}, i=1,2, \cdots, N$, output the allocation result $P_{1}, P_{2}, \cdots, P_{N}$, otherwise, turn to Step4;

Step4 Find $k$ which satisfies $P_{k \max } \leq \frac{P_{T}}{N}$, $P_{(k+1) \max }>\frac{P_{T}}{N}$, make $P_{i}=P_{i \max }, \quad i=1,2, \cdots, k$;

Step5 Let

$$
\begin{aligned}
S & :=S \backslash\left\{P_{1}, P_{2}, \cdots, P_{k}\right\}=\left\{P_{k+1}, P_{k+2}, \cdots, P_{N}\right\} \\
& :=\left\{P_{1}, P_{2}, \cdots, P_{N-k}\right\}, \\
P_{T} & :=P_{T}-\sum_{i=1}^{k} P_{i \max }, N:=N-k, \text { turn to Step3. }
\end{aligned}
$$

Flow chart of the algorithm is shown in figure 2.

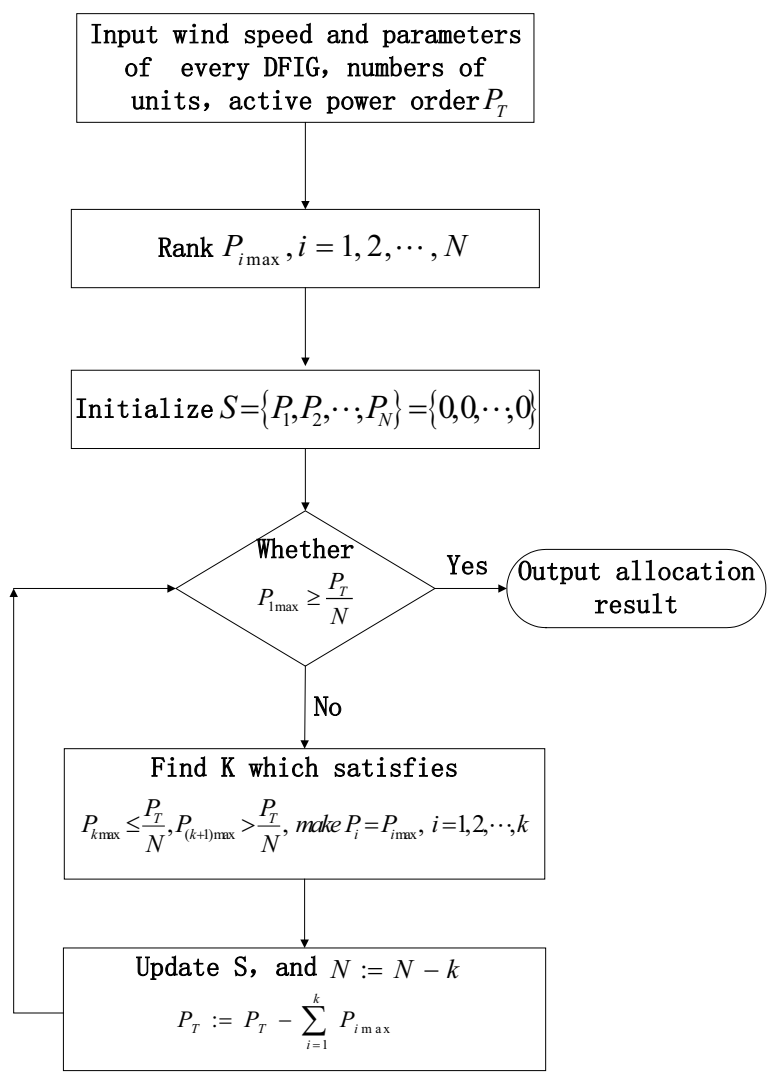

Fig.2 Flow chart of active power allocation

This algorithm is suitable to $\sum_{i=1}^{N} P_{i \min } \leq P_{T}$.

Otherwise, some units must be shut down. 


\section{Case Study}

A wind farm consists of 30 wind turbines with double fed induction generators, each wind turbine equipped with a $0.69 \mathrm{KV} / 20 \mathrm{KV}$ box transformer, air density in wind farm being $1.225 \mathrm{Kg} / \mathrm{m}^{3}$. Simple layout of the wind farm is shown in figure 3 . The parameters of DFIG are shown in table 1 , the input wind speed of every unit is shown in table 2. The active power order from power dispatching center is $21 \mathrm{MW}$, and the reactive power demand of power grid is $16.5 \mathrm{Mvar}$.

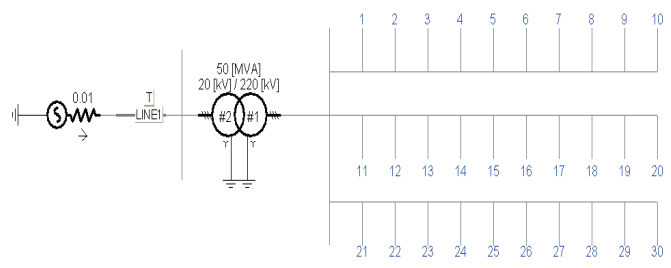

Fig.3 Simple layout of wind farm

Tab.1 The parameters of one DFIG

\begin{tabular}{cc}
\hline Parameter & DFIG \\
\hline Rated power & $1.5 \mathrm{MW}$ \\
Stator self-inductance & $5.6436 \mathrm{mH}$ \\
Stator leakage inductance & $0.1687 \mathrm{mH}$ \\
Rotor leakage inductance & $0.1337 \mathrm{mH}$ \\
Mgnetizing inductance & $5.4749 \mathrm{mH}$ \\
Maximum rotor current & $1200 \mathrm{~A}$ \\
\hline
\end{tabular}

Tab.2 Wind speed of every wind turbine $(\mathrm{m} / \mathrm{s})$

\begin{tabular}{lclc}
\hline 1\# turbine & 11.1 & 16\# turbine & 10.2 \\
2\# turbine & 11.2 & 17\# turbine & 10.9 \\
3\# turbine & 10.6 & 18\# turbine & 10.6 \\
4\# turbine & 8.1 & 19\# turbine & 10.4 \\
5\# turbine & 8.0 & 20\# turbine & 10.5 \\
6\# turbine & 7.8 & 21\# turbine & 9.6 \\
7\# turbine & 7.6 & 22\# turbine & 10.8 \\
8\# turbine & 7.5 & 23\# turbine & 8.5 \\
9\# turbine & 7.7 & 24\# turbine & 8.6 \\
10\# turbine & 7.6 & 25\# turbine & 9.7 \\
11\# turbine & 9.5 & 26\# turbine & 9.9 \\
12\# turbine & 9.6 & 27\# turbine & 9.5 \\
13\# turbine & 9.6 & 28\# turbine & 9.4 \\
14\# turbine & 9.3 & 29\# turbine & 9.5 \\
15\# turbine & 9.2 & 30\# turbine & 9.1 \\
\hline
\end{tabular}

In this case, $N=30, P_{T}=21 \mathrm{MW}$, $Q_{N}=16.5 \mathrm{Mv}$ ar. Given the current wind speed, the $P_{i \max }, i=1,2, \cdots, 30$ are shown in table 3 .

The maximum active power generated by wind farm is $23.538 \mathrm{MW}$, however, the order from power dispatching center is $21 \mathrm{MW}$ and then the wind power curtailment happens. From table 3 we can see that 10 units fail to output the average active power (i.e.
$\frac{P_{T}}{N}=0.7 \mathrm{MW}$ ), so Theorem 2 is used. According to Theorem 2, 4\# 10\#, 23\#, 24\#, 30\# output the maximum active power, the other 20 units will output active power 16.198MW, that is to say, every unit needs to output 0.809MW. $P_{11 \max } \sim P_{15 \max }, P_{21 \max }, P_{27 \max } \sim P_{29 \max }$ are all less than $0.809 \mathrm{MW}$, so they output the maximum active power. Then the other 11 units will generate 9.246MW, and every unit needs to output $0.840 \mathrm{MW}$. Go on with this algorithm until all 30 units are assigned. The active power allocation result is shown in table 4 . Now according to this active power allocation plan, the reactive power limit of the whole wind farm is 16.724Mvar over $Q_{N}$, so the additional reactive power compensation device does not need to work.

Tab.3 $P_{i \max }$ of every wind turbine (MW)

\begin{tabular}{llll}
\hline$P_{1 \max }$ & 1.245 & $P_{16 \max }$ & 0.966 \\
$P_{2 \max }$ & 1.279 & $P_{17 \max }$ & 1.179 \\
$P_{3 \max }$ & 1.084 & $P_{18 \max }$ & 1.084 \\
$P_{4 \max }$ & 0.483 & $P_{19 \max }$ & 1.024 \\
$P_{5 \max }$ & 0.466 & $P_{20 \max }$ & 1.054 \\
$P_{6 \max }$ & 0.432 & $P_{21 \max }$ & 0.805 \\
$P_{7 \max }$ & 0.399 & $P_{22 \max }$ & 1.147 \\
$P_{8 \max }$ & 0.384 & $P_{23 \max }$ & 0.559 \\
$P_{9 \max }$ & 0.415 & $P_{24 \max }$ & 0.579 \\
$P_{10 \max }$ & 0.399 & $P_{25 \max }$ & 0.831 \\
$P_{11 \max }$ & 0.780 & $P_{26 \max }$ & 0.883 \\
$P_{12 \max }$ & 0.805 & $P_{27 \max }$ & 0.780 \\
$P_{13 \max }$ & 0.805 & $P_{28 \max }$ & 0.756 \\
$P_{14 \max }$ & 0.732 & $P_{29 \max }$ & 0.780 \\
$P_{15 \max }$ & 0.709 & $P_{30 \max }$ & 0.686 \\
\hline
\end{tabular}

If we follow the other active power allocation plan (table 5), the reactive power limit of the whole wind farm is $16.008 \mathrm{Mvar}$ which is less than $Q_{N}$, so the first layer allocation plan is invalid. We also made other active power allocation plans and $16.724 \mathrm{Mvar}$ is the maximum value, i.e. $Q_{F \max }$ is $16.724 \mathrm{Mvar}$, Theorem 2 is correct. 
Tab.4 Active power allocation result (MW)

$\begin{array}{llll}\text { 1\# turbine } & 0.841 & \text { 16\# turbine } & 0.841 \\ \text { 2\# turbine } & 0.841 & \text { 17\# turbine } & 0.841 \\ \text { 3\# turbine } & 0.841 & \text { 18\# turbine } & 0.841 \\ \text { 4\# turbine } & 0.483 & \text { 19\# turbine } & 0.841 \\ \text { 5\# turbine } & 0.466 & \text { 20\# turbine } & 0.841 \\ \text { 6\# turbine } & 0.432 & \text { 21\# turbine } & 0.805 \\ \text { 7\# turbine } & 0.399 & \text { 22\# turbine } & 0.841 \\ \text { 8\# turbine } & 0.384 & \text { 23\# turbine } & 0.559 \\ \text { 9\# turbine } & 0.415 & \text { 24\# turbine } & 0.579 \\ \text { 10\# turbine } & 0.399 & \text { 25\# turbine } & 0.831 \\ \text { 11\# turbine } & 0.780 & \text { 26\# turbine } & 0.841 \\ \text { 12\# turbine } & 0.805 & \text { 27\# turbine } & 0.780 \\ \text { 13\# turbine } & 0.805 & \text { 28\# turbine } & 0.756 \\ \text { 14\# turbine } & 0.732 & \text { 29\# turbine } & 0.780 \\ \text { 15\# turbine } & 0.709 & \text { 30\# turbine } & 0.686\end{array}$

Tab.5 Other active power allocation plan (MW)

\begin{tabular}{|c|c|c|c|}
\hline 1\# turbine & 1.000 & 16\# turbine & 0.900 \\
\hline 2\# turbine & 1.000 & $17 \#$ turbine & 1.000 \\
\hline 3\# turbine & 1.000 & $18 \#$ turbine & 1.000 \\
\hline 4\# turbine & 0.453 & 19\# turbine & 1.000 \\
\hline 5\# turbine & 0.446 & 20\# turbine & 1.000 \\
\hline $6 \#$ turbine & 0.402 & $21 \#$ turbine & 0.705 \\
\hline 7\# turbine & 0.300 & 22\# turbine & 1.000 \\
\hline $8 \#$ turbine & 0.374 & $23 \#$ turbine & 0.545 \\
\hline 9\# turbine & 0.405 & $24 \#$ turbine & 0.535 \\
\hline 10\# turbine & 0.359 & 25\# turbine & 0.831 \\
\hline $11 \# \mathrm{t}$ urbine & 0.680 & $26 \#$ turbine & 0.800 \\
\hline $12 \#$ turbine & 0.605 & $27 \#$ turbine & 0.700 \\
\hline 13\# turbine & 0.731 & 28\# turbine & 0.700 \\
\hline 14\# turbine & 0.645 & $29 \#$ turbine & 0.690 \\
\hline $15 \#$ t urbine & 0.666 & $30 \#$ turbine & 0.528 \\
\hline
\end{tabular}

With method of two layers power allocation, active power and reactive power generated by wind farm both meet the requirements.

\section{Conclusions}

The method of two layers power allocation not only meets the requirements of power grid, but also provides each unit with enough margins. After average distribution of active power, the wind farm can generate the maximal reactive power at the current wind speed and it will respond to emergency quickly.

In actual large scale wind farm, there exist a great number of units, so the method proposed in this paper presents an obvious advantage. When the input wind speed gets close to rated wind speed or exceeds the rated wind speed, the same active power order will cause the wind power curtailment of many units. In other words, in the area where wind power curtailment happens frequently, the proposed method can provide reactive power compensation in a larger range for the power grid and satisfy the power grid's requirements of active power and reactive power.

\section{Acknowledgements}

This paper was supported by the Fundamental Research Funds for the Central Universities of China.

\section{References}

1. M. J. Hossain, H. R. Pota, V. A. Ugrinovskii and R. A. Romos, Simultaneous STATCOM and pitch angle control for improved LVRT capability of fixed-speed wind turbines, IEEE Transactions on Sustainable Energy. 1(3) (2010) 142-151.

2. H. Geng, C. Liu and G. Yang, LVRT capability of DFIGbased WECS under asymmetrical grid fault condition, IEEE Transactions on Industrial Electronics. 60(6) (2013) 2495-2509.

3. X. D. Zhu, Current China's wind power abandon wind, Energy and Energy Conservation. 10 (2012) 30+67.

4. W. Li and D. Truong, Stability enhancement of a power system with a PMSG-based and a DFIG-based offshore wind farm using a SVC with an adaptive-network-based fuzzy inference system, IEEE Transactions on Industrial Electronics. 60(7) (2013) 2799-2807.

5. P. Vuorenpaa. P and Jarventausta, Enhancing the grid compliance of wind farms by means of hybrid SVC, in proc. PowerTech. IEEE (Trondheim, 2011), pp. 1-8.

6. S. Sun, Y. Cheng, D. S. Han, P. Zhao and Q. B. Mao, Research on improving low voltage ride through of a wind farm by SVC, China Electric Power(Technology Edition). (1) (2013) 47-51.

7. F. F. Ji, L. D. Zhou, G. Yao and C. Chen, Static var compensator based on the method of synchronous symmetrical component, Proceedings of the CSEE. 25(6) (2005) 27-32.

8. M. Marta, J. A. Suul and T. Undeland, Low voltage ride through of wind farms with cage generators: STATCOM versus SVC, IEEE Transactions on Power Electronics. 23(3) (2008) 1104-1117.

9. W. Qiao, G. K. Venayagamoorthy and R. G. Harley, Real-time implementation of a STATCOM on a wind farm equipped with doubly fed induction generators, IEEE Transactions on Industry Applications. 45(1) (2009) 98-107.

10. L. Wang and C. Hsiung, Dynamic stability improvement of an integrated grid-connected offshore wind farm and marine-current farm using a STATCOM, IEEE Transactions on Power Systems. 26(2) (2011) 690-698.

11. C. Han, A.Q. Huang, M.E. Baran, S. Bhattacharya, W. Litzenberger, L. Anderson, A. L. Johnson and A. Edris, STATCOM impact study on the integration of a large wind farm into a weak loop power system, IEEE Transactions on Energy conversion. 23(1) (2008) 226-233.

12. C. F. Wang, J. Liang, L. Zhang and X. S. Han, Reactive power and voltage control strategy for wind farm based on STATCOM, Proceedings of the CSEE. 30(25) (2010) 2328. 
13. S. Q. Li, W. X. Xu, W. Z. Li, DC capacitor voltage balancing control for cascade STATCOM in wind farm, Transactions of China Electrotechnical Society. 30(25) ( 2010) 23-28.

14. Q. S. Xu, H. L. Zhang, C. Y. Zhou and T. Jiang, Lowvoltage ride-through capability for wind generators based on dynamic voltage restorers, Journal of North China Electric Power University(Natural Science Edition). 38(5) (2011) 6-10.

15. Y. Q. Lang, X. G. Zhang, D. G. Xu, H. F. Ma and Hadianmrei S.R, Reactive power analysis and control of double fed induction generator wind farm, Proceedings of the CSEE. 27(9) (2007) 77-82.

16. R. Li, F. Tang, Y. P. Liu, T. Q. Wang, J. H. Jia and L. Cheng, A new scheme of reactive power compensation and voltage control for DFIG based wind farm, Proceedings of the CSEE. 32(19) (2012) 16-23+180.

17. X. G. Zhang, Y. C. Liu, Y. Hai and D. G. Xu, Improved voltage control strategy of double-fed induction generators wind farm in distribution networks, Proceedings of the CSEE. 30(7) (2010) 29-35.

18. X. L. Zhu, Y. Zhang, K. Gao, Q. Li, X. Z. Du and T. H. Liu, Research on the compensation of reactive power for wind farms, Power System Protection and Control. 37(16) (2009) 68-72+76

19. L. G. Meegahapola, S. R. Abbott, D. J. Morrow, T. Littler and D. Flynn, Optimal allocation of distributed reactive power resources under network constraints for system loss minimization, in Power and Energy Society General Meeting, (2011),pp.1-7.

20. X. W. Wei, X. Y. Qiu, X. Y. Li and Z. J. Zhang, Multiobjective reactive power optimization in power system with wind farm, Power System Protection and Control. 38(17) (2010) 107-111

21. L. Zhao and J. H. Lv, Multi-objective reactive power optimization of wind farm based on improved genetic algorithm, Electric Power Automation Equipment. 30(10) (2010) 84-88.

22. J. J. Zhao, Y. Fu and D. D. Li, Reactive power optimization in distribution network considering reactive power regulation capability of DFIG wind farm, Electric Power Automation Equipment. 35(11) (2011) 33-38.

23. N. Chen, L. Z. Zhu and W. Wang, Strategy for reactive power control of wind farm for improving voltage stability in wind power integrated region, Proceedings of the CSEE. 29(10) (2009) 102-108. 